\title{
Historical Ecology in the Pacific Islands: Prehistoric Environmental and Landscape Change. Edited by Patrick V. Kirch and Terry L. Hunt, New Haven: Yale University Press (1997). 331 pp.
}

\author{
Reviewed by Charles J. Stevens, Program in Population Research, \\ University of California - Berkeley
}

Twelve papers presented at the day-long Seventeenth Pacific Science Congress in Honolulu in June,1991 comprise this interdisciplinary volume. Expanding on Fosberg's 1961 symposia, and re-presenting the oft-heard exaltation--that islands are the ideal natural-historical "laboratories" and exemplars of fragile environments, the editors present the islands of Australia, New Guinea, and the Pacific as consummate locales on which to "advance the young but rapidly growing field of historical ecology" (p. 1). The papers document the impact of Pleistocene hunter-gatherers, oceanic colonialists, and bush fallow horticulturalists, on the topography and biota of largely insular and bounded island environments-, relying on the vast region's archaeological, palynological, and paleontogical record.

Kirch's "Introduction" presents an overview of archaeological and ecological research in the Pacific and outlines the symposium's goal of charting changes in Pacific Island landscapes through time. Although the ecological attenuation of islands and their relative isolation renders island ecosystems stable over the long haul prior to human occupation, Kirch notes that these same features make island ecosystems vulnerable to rapid environmental alterations after people arrive, and especially after the arrival of Europeans. Human colonization of the Pacific left concrete and archaeologically detectable evidence.

The papers present the results of ongoing research in the ecological prehistory of Hawai'i, New Zealand, New Guinea, Australia, and sites in Central and Western Polynesia (Ofu, Samoa, Mangaia, Aitutaki, Atiu, Mo'orea, and Tahiti). Reports are lacking for Micronesia, Tonga, Fiji, and Melanesia (other than New Guinea and the briefly mentioned Bismarck Archipelago). The volume is concerned only with Pacific Islands, and no explicit comparison is made to the islands of the Caribbean, Indian Ocean, or the Indonesian archipelago. All of the papers are concerned with a desire not only to document the consequences of human occupation of small and bounded ecosystems, but also to note the variations in disruptions caused by the colonization of ecologically distinct islands or island regions. It is no mean task to sort out the effects of direct human action, perdition, and foraging by the pigs and rats brought by humans from the effects of natural fluctuations in sea level and climate. Accordingly, an important contribution of the volume lies in its chronology of landscape alterations in a number of islands. The research documents the arrival to various islands of humans, the sweet potato, coconuts, and pigs, and further notes the existing gaps in the archaeological record of plant and animal (especially human) colonization of Pacific islands. The volume's papers clearly document the environmental disruptions brought by Melanesians and Polynesians forging anthropocentric ecosystems on previously thoroughly natural environments.

Following the Introduction, the papers are nicely organized, both temporally and geographically. We are presented first with the earliest evidence of human impacts on 
island ecosystems, Pleistocene hunter-gatherers in Greater Australia at 40,000 BP, and the volume concludes with papers by Anderson and Athens evaluating the environmental consequences of the most recent Polynesian colonizations of Hawai'i and New Zealand. Not surprisingly, there is frequent criticism in the text of Nunn's $(1988,1991)$ assertion that human impact on island ecosystems has been exaggerated, and that the role of humans as sole actors in environmental change has been overly dramatized. This argument is also presented by O'Neill (1994), whose synoptic review of Pacific Island history is not cited in the volume's papers, but whose punctuated equilibrium model of ecological change is generally in concert with the volume's viewpoint. Only one paper, that of Orliac on the Papeno'o Valley in Tahiti, attributes greater cause on landscape change to natural events than to human action.

Although there is no clear chronology for the progressive colonization of Greater Australia (the single landmass of Australia and New Guinea existing during the Pleistocene), Allen notes in the first report that archaeologically visible populations appear nearly simultaneously across all of the Australian Pleistocene continent by about 40,000 BP. In Allen's scenario, small numbers of Pleistocene hunter-gatherers systematically colonized the landmass, had frequent interisland crossing to the then--visible islands of near Melanesia, colonized Tasmania by $35,000 \mathrm{BP}$, and affected the environment in archaeologically perceivable ways. The considerable contemporaneity of humans and now-extinct megafauna on the Pleistocene continent, and the successful predation by hunters on Bennett's Wallaby (Macropus rufogriseus) for 20,000 years, suggest a deliberate hunting strategy not indicative of the blitzkrieg approach offered as explanation for North American megafauna extinction. The connection between megafauna extinction and human occupation of the Sahul is unclear, notes Allen (p. 27-28), and its clarification requires a resurrection of paleodemographic research and continued environmental archaeology of Pleistocene colonizers. With a probable date of 9,000-10,000 BP for the development of horticulture in New Guinea, the increasing pace of environmental disruption in the early Holocene in Greater Australia is likely attributable to the more deliberate alterations in the landscape associated with and required for agriculture.

Climatic change at the end of the Pleistocene permitted the introduction of horticulture into the highlands of the New Guinea cordillera and initiated a series of environmental changes. In Golson's model, climate change induced slow postdisturbance forest regeneration, slowed the accumulation of soil fertility, and, particularly with the high soil fertility requirements of introduced sweet potatoes (Ipomoea batatas), frequent forest clearing was required and primary forests were ultimately replaced with "increasingly degraded secondary growth" (p. 41). The faunal record reveals a period of forest degradation around $4000 \mathrm{BP}$ and again in $1200 \mathrm{BP}$ with a concomitant reduction in montane species diversity. Pollen diagrams, although unevenly distributed spatially in New Guinea and seldom dated to earlier than the mid-Holocene, still disclose the apparent expansion of an agrosilviculture of root crops and Casuarina tree species. The consequences of this agroforestry were ecosystem simplification, reduction in forests, increasing grasslands, and reduced vertebral species diversity. Golson's task, to present a general ecological history of a sizable landmass that has substantial geographical and cultural diversity, is ambitious. His linear model may hold less well as more is learned about local variation in environmental change and, as Golson himself observes, more archaeological data are needed to better understand changes in pig husbandry and its effects in the precontact period. 
Interdisciplinary work involving archaeologists, ethnobotanists, and agroecologists may be able to better answer a number of questions raised by Golson's article: Does "secondary growth" necessarily return a diminished soil fertility? Evidence from research in agroecology and soil sciences suggest that secondary forests with high floral species diversity may produce more fertile soils than those found in primary tropical forests where localized tree species diversity may be small (Van Wambeke 1992). The most significant issues remain: What is the extent of geographical variation from Golson's linear model of change in the new Guinea highlands? and What ecological and cultural characteristics may be complicit in this variation?

The devastation of avian species that accompanied the Polynesian colonization of Oceanic Pacific islands is now well recognized, substantially from the work of David Steadman. In his contribution to this volume, Steadman describes the reciprocal relationships between humans and birds in Polynesia and Melanesia, first noting the extinction and extirpation of bird species due to direct human predation and other anthropogenic factors (habitat loss, forests destruction, and predation by pigs, rats and dogs). Secondly, Steadman notes the utility of birds to the Polynesians as food, navigation aides, and sources of feathers and bones for tools. Drawing on the ethnographic record to document the relationship between birds and Polynesians, Steadman describes the increasing pace of avian and habitat extinction in Polynesia since European contact when market production and population pressure required expansion of agriculture and exacerbated deforestation. He calls for expanded research into the ecology of Polynesian bird species and for interdisciplinary and applied research oriented toward the possible repatriation of bird species to islands from which they were extirpated.

The Polynesian colonizers of the Oceanic islands of the South Pacific introduced roughly 24 species of cultivars, since few edible plants were endemic to the islands prior to their colonization (see, for example, J. Barrau 196, 1974). Agriculture on the tropical islands required forest clearing with fire and stone and shell tools. This increased soil erosion and led to decreasing genetic diversity of flora and fauna, as has been increasingly well documented in the archaeological record of the region. The soil erosion resulted in silting of lagoons, alterations of the near-shore marine environment, and silting of stream beds. Some of the landscapes resulting from this erosional process were particularly well suited to the growing of taro, as Spriggs has noted in this volume. The question becomes whether some of these landscape alterations were intentional, and not accidentally anthropocentrically beneficial. Other papers in the volume present case studies of specific ecological histories on particular islands or in particular time periods. Spriggs' and Steadman's papers, however, may be of most interest to political ecologists and ecological archaeologists not working in the Pacific, as they present discussions of general patterns of topographical change and species extinction. Of particular interest is Spriggs' review of the inherent difficulties of archaeological research in prehistoric agriculture, and his paper offers a perceptive discussion of the benefits and the limitations of archaeology in the study of agricultural development and environmental change.

The historical ecology of Ofu Island in Samoa is presented by Hunt and Kirch, whose field research focused specifically on Ofu's occupational history and affiliated environmental change. Their resulting chronology offers a colonization date of 3257 to 2879 BP based on ${ }^{14} \mathrm{C}$ dating, and they present a six-stage process of habitation and technological change and associated environmental change. Their model may have relevance to other Pacific islands, but they caution that variability in environmental change among Pacific islands should be anticipated, based on differences in subsistence 
composition and the unique historical and geographical characteristics of many islands. In Ofu's case, coastal terrace expansion resulted from a combination of human and natural events. Explication of this combined pattern in different islands is required to understand the variable impacts of human occupation of small islands. Explication of environmental change on specific islands characterizes the chapters by Allen and Kirch in the Cook Islands (Aitutaki and Mangaia respectively), Parkes' comparative sediment analysis of lakes on Atiu Island and Mo'orea, and Orliac's survey of the Papeno'o Valley of Tahiti. Each of these papers show similar patterns of environmental alteration in loss of terrestrial and marine species, but they also begin to demonstrate localized differences in the extent and the proximate causes of archaeologically detectable environmental change. In this endeavor, the authors candidly admit the limitations of current archaeological knowledge and the need for continued interdisciplinary research. In all of these papers, as well, clear evidence is presented that, with the exception of Orliac's work in Tahiti, human activity had enormous effects on the natural environment of Pacific Islands.

The archaeological portion of writing deep historical ecologies is superbly presented in Kirch's and Hunt's volume. No discussion adequately captures another part of the story of Pacific Islander colonization, however that of islanders, who, despite initial destruction, maintained long-term, sustainable agriculture, pig and chicken husbandry, and harvesting of marine resources for as long as 2,700 years. In some respects it seems that islanders were as accomplished natural historians and agroecologists as they were navigators. Investigating this aspect of the political ecology of the Pacific will benefit from a closer collaboration among geographers, cultural anthropologists, and prehistorians. In this scholarly context, theoretical differences and concerns about doing science, interpretation, or advocacy, may well impede effective interdisciplinary détente, and Kirch implicitly draws attention to this in his article on the changing landscape of Mangaia (p. 165).

One example of collaboration between an archaeologist and a cultural anthropologists is Kirch's own work, a joint ethnohistorical work with Marshall Sahlins (1992) that deals with changes in both political and environmental landscapes. In this volume, Kirch (p.164) again approaches cultural anthropological themes in his presentation of a "mytho-praxis of nineteenth- century Mangaian society in terms of the Longue durée." Here Mangaian relations of production are diagramatically depicted as flows of information and resources where the god Rongo receives ceremonial taro and human sacrifices through the chiefly class and bestows, in return, fertility to the soil and mana to the chiefs. But there is something missing from Kirch's diagram. Although the chiefs (Te Mangaia), gods, cultivars, and the structure of reciprocal relations are shown, there are no producers--no commoners who were actually engaged in agriculture or fishing. Further archaeological investigations into the actual production of material life and the associated documentation from centralized villages during World War II would be useful. Some homesteads were maintained in the bush for long periods. In both instances, in re-establishing homesteads in the bush, farmer families reconstructed the settlement patterning and a circumhousehold landscape more common in the pre-European era. Contemporary smallholder agriculturalists have a deep historical recollection of their-land management patterns and, in investigating these historical house mounds, a tentative link between the past uses of island environments and the contemporary exploitation of resources could be created through joint historical archaeological research and historical ethnography. An archaeology of the material life, as evident in the archaeological and ethnohistorical record of agricultural production, may help explain the variation in environmental disruption and clarify aspects of the long-term sustainability of farinaceous agriculture. 
Such a collaboration may also allow for an archaeology of smallholder agriculturalists. This is much needed because the producers of agriculture, those who directly interacted with the environment, are usually absent from archaeological research concerned with explication of more general political processes. In this endeavor, the collaboration of cultural anthropologists and archaeologists may help prove as beneficial as the interdisciplinary collaboration of archaeologist, palynologists, and paleoenvironmentalists in this important volume.

The importance of interdisciplinary research in political ecology is clearly and cohesively demonstrated in this volume, which represents both the current status and the future direction of research in ecological archaeology in the Pacific. As such, it is an invaluable resource for anyone with interests in deep ecological history and in the methodology of historical ecological research. Cultural anthropologists may quibble about the strictness of linear modeling in archaeology, and some may question the utility and salience of optimal foraging models for understanding contemporary islanders subsistence activities. But these models, like the one offered by Anderson in this volume, are efficacious in explaining the prehistoric human/environment interaction as evidenced in the archaeological record.

\section{References Cited:}

Barrau, Jacques.

1961. Subsistence Agriculture in Polynesia and Micronesia. Bernice P. Bishop Museum Bulletin 223. Honolulu: Bernice P. Bishop Museum.

Barrau, Jacques.

1965 L'Humide et le Sec.: An Essay on Ethnobiological Adaptation to Contrastive Environments in Indo-Pacific Area. Journal of the Polynesian Society 74(3):329346.

Nunn, Patrick D.

1988. Recent Environmental Changes Along Southwest Pacific Coasts and the Prehistory of Oceania: Developments of the Work of the Late John Gibbons. Journal of Pacific Studies 14(1):42-58.

1991. Keimami sa vakila na liga ni Kalou (Feeling the Hand of God): Human and Non-Human Impacts on Pacific Island Environments. Honolulu: Environment and Policy Institute, East-West Center Occasional Papers No. 13.

O'Neill, J.R.

1994. Of Rats and Men: A Synoptic Environmental History of the Island Pacific. Journal of World History 5(2): 299-349.

Sahlins, Marshall.

1992. Anahulu: The Anthropology of History in the Kingdom of Hawai'i, volume I: Historical Ethnography. and Patrick Kirch. Anahulu: The Anthropology of History in the Kingdom of Hawai'i , volume II, The Archaeology of History. Chicago: The University of Chicago Press.

Thaman, R. R.

1994. Pacific Island Agroforestry: An Endangered Science. In Morrison, John, Paul Geraghty, and Linda Crowl (eds.) Land Use and Agriculture: Science of Pacific Island Peoples, Volume II. Honolulu: Institute of Pacific Studies.

Van Wambeke, Armand.

1992. Soils of the Tropics: Properties and Appraisals. New York: McGraw Hill. 